\title{
Towards a sustainable society: a profile of social accents
}

\author{
André Pelser \\ Department of Sociology \\ University of the Free State \\ BLOEMFONTEIN
}

\author{
Christo Heunis \\ Centre for Health Systems Research \& \\ Development \\ University of the Free State \\ BLOEMFONTEIN
}

\begin{abstract}
Towards a sustainable society: a profile of social accents

Against the background of the pending global environmental crisis, this article argues that the solutions to the crisis are as much part of the sociopolitical field as they are of the technological and scientific fields. Consequently a number of social accents that should be addressed in the attempt to achieve a sustainable society are elucidated. These accents include revision of current value systems characterized mainly by economic variables, the curbing of population growth rates, expansion of human rights, alleviation of poverty, universal access to education, health services and family planning. The redistribution of and access to natural resources, community involvement and the fostering of a political will to address these issues should also be reflected on
\end{abstract}

\section{Preface}

The most critical environmental problems, from which all others arise, are our own attitudes and values (Raven et al., 1993:564).

The biggest challenges and problems facing modern societies arise from the interaction between people and their environment. In fact, warnings are widely acknowledged that mankind is heading for a global environmental crisis (or crises, as some believe) of a catastrophic extent because of the nature of this interaction. Increasing awareness of the potential seriousness of such an environmental crisis has placed environmental issues high on socio-political and academic agendas, especially since the sixties. Although broad consensus has been reached with regard to the reality of the pending crisis, the extent and seriousness of many environmental questions still remain a topic of debates. At the same time, it seems as if there is little consensus regarding the causes of and possible solutions for the crisis: what is regarded by one interest group as a cause, is often seen by another as a solution. 
Nevertheless, there seems to be wide consensus that a shift in emphasis and a reorientation in all areas are crucial in order to prevent the realization of some of the envisaged scenarios. In other words: the answer(s) to the environmental crisis is (are) just as much part of the social, economic and political fields as they are of the technological and scientific fields. We will therefore argue that strategies which are limited to only the latter two fields in order to achieve sustainability, is a futile exercise. After all, human beings are at the centre of the environmental crisis, both as catalysts and victims. This article is therefore embedded in the principle that a necessary (although not sufficient) step towards coping with environmental problems is the adoption of an environmental ethic which stresses the importance of humanity living in harmony with ecological systems and creating human societies that are permanently sustainable. As such our argument departs from the ecological social paradigm (ESP) which, since the early seventies, has started to redefine the way human beings used to perceive their environment and emphasize the interdependent relationship which exists between humanity and the natural world. Against this background, a number of social accents that should be considered to be essential prerequisites for a sustainable society, are elucidated in this article. More specifically, this discussion involves an identification of the social conditions for a sustainable society and an outline of those values that ought to be in congruency with such a system. For this purpose the nature of the environmental crisis is outlined in order to sketch the context in which the call for sustainable development arises.

\section{The nature of the environmental crisis}

Against the background of the "Earth Summit" held in 1992 and a growing universal concern about the conservation of the environment, it has become unrealistic to address the themes of sustainable development and sustainable societies without involving the environmental crisis and the resource basis of the earth as central issues. With the world population approaching the six billion mark, population issues are paramount in the search for sustainability. Some comments are made in the discussion with regard to this, after which the issues of pollution and the depletion of resources are briefly considered as two further umbrella components of the environmental crisis.

\subsection{Overpopulation and overconsumption}

Few issues in the environmental debate are so controversial and sensitive as that of "population". The fact that some populations, and especially human populations, increase much faster than the resources on which they depend for their survival, is not a recent reason for concern. Scientists and philosophers such as Plato, Aristotle, Benjamin Franklin and of course Thomas Malthus in his famous Essay on the Principles of Population (1798) have all entered the 
population debate at one stage or another - a debate that was fuelled by pressing questions such as: How many people are 'too many'? How many people can be sustained by the natural resources of the earth? How can mankind's impact on the earth be controlled in order to ensure that the planet's life-supporting systems do not fall apart?

The past few decades have seen these and similar questions evolve into an emotional and highly politicized debate. Different interest groups and positions have been identified as different answers and solutions were offered to the question to what extent growing populations should be blamed for the environmental problems which we face today. Not only are the extreme positions in this debate of an ideological nature, but they are also anchored in political and economic agendas and further fanned by fierce competition. One argument is represented by the neo-Malthusians, who emphasize the negative effects of population growth. This school argues that as populations are potentially able to grow in an unlimited manner while resources are physically limited - for example, the available agricultural land is limited - "over-population" is inevitable. Various prominent authors in the industrialized, developed countries (especially those of the Northern hemisphere) thus blame the rapidly growing population numbers in the poorer, developing countries (especially those of the Southern hemisphere) for the current environmental crisis. Supporters of the overpopulation argument stress the fact that famine, especially in the rural areas of the developing countries, stems directly from high population growth rates that cannot be reconciled with the carrying capacity of the environment in these countries. For example, approximately one third of the population of sub-Saharan Africa is chronically under-nourished, while the food requirement of this region is expected to double during the next two decades, given the projected population growth rates (Dyson, 1994:375-383)

The other side of the coin is represented by those who hold a more enlightened, but equally simplistic view: Over-consumption of resources by the prosperous populations of the industrialized countries and the privileged minorities in the developing countries, and not over-population per $s e$, is responsible for global environmental degradation and the accompanying social problems. This point of view is often kindled by accusations of an inappropriate technology, social inequality and exploitation, which all serve as a shield against the onslaught of the "over-population"-theory supporters. The "over-consumption" school points out that, although the developed countries accommodate only $20 \%$ of the world population, they use $80 \%$ of the resources. In fact, almost $70 \%$ of all metals, $85 \%$ of the wood on earth and $60 \%$ of the total food yield are consumed by the elite in the South and the wealthy countries in the North (Lass, 1995:3). The lifestyle of the average European therefore produces 2000 times more toxic waste than that of the average peasant in Africa. If these levels persist, the 
approximately 57 million people who will be born into a high-consumption lifestyle during the 1990s will pollute the earth far more than the expected 911 million who will be born during the same period in the developing countries of Asia, Africa and Latin America.

A third school in the population debate believes that there is no problem. According to this school human beings are the most important resource and human innovation will ensure that development and technology will be able to handle any crisis that may occur. In the meanwhile, more people mean larger markets for products. At the root of this argument is the assumption that economic development and growth are prerequisites for success in the pursuit of a sustainable existence. However, it is at this point that a paradox presents itself: Thoughtless economic development is an important factor in the degradation of the environment, while the latter factor plays a key role in the impoverishment of rural populations. In fact, it is the emphasis on economic and technological development (in an attempt, inter alia, to balance the growing population numbers) which in many respects is fundamental to the next two environmental problems.

\subsection{Depletion of resources}

A direct consequence of increasing population pressure and over-consumption is the depletion of life-supporting resources. Although some problems in this regard are of a regional nature, it is especially the global issues that are in the limelight. Examples of this problem are the deforestation of tropical rain forests and the consequent atmospheric changes (such as the so-called greenhouse effect), the disappearance of species and habitats, the breakdown of the ozone layer which in turn can be traced to increasing levels of pollution in the atmosphere, as well as soil erosion owing to over-grazing and encroachment of the desert. The decrease in the available agricultural land due to the increasing loss of fertile top-soil is widely regarded as a crucial cause of the declining food production in developing rural areas. More recently, the alarm-bells started ringing with the realization that the earth may be faced with a water crisis. It is estimated that the global water requirement doubles every 21 years, while approximately 80 countries are already experiencing water shortages (Capraro, 1995:4). Eighty percent of all deaths in the developing countries have already been associated with polluted water or a general lack of water. The inevitable results of an ever decreasing water supply are, among others, food shortages, political tension and conflict.

\subsection{Pollution}

Air, water and soil pollution are probably more familiar to many people than most of the other environmental problems. One of the most wide-ranging problems that can be listed here, is the increasing release of carbon dioxide $\left(\mathrm{CO}_{2}\right)$ as a 
result of the burning of fossil fuels (coal, oil and natural gas) - a phenomenon which, in certain scientific circles, is held responsible for the alleged gradual heating of the atmosphere of the earth, for example. The elimination and associated burning of the tropical forests in developing countries in an attempt to supply agricultural land and grazing for a growing population, further contribute to the above-mentioned problem. Contrary to this, pollution problems such as acid rain, oil pollution by tankers and the spilling of chemical and nuclear waste are typical pollution issues that are created mainly by the industrialized countries.

When we look specifically at South Africa, it becomes evident that the country is in many respects a micro-cosmos of the issues regarding population, pollution and resource depletion with which the whole world is confronted. The South African environment is, however, not only hampered by the typical problems that are associated with developing countries (such as a high population growth), but also by those that are associated mainly with industrialized countries (for example air pollution)

During the period 1970-1993 the South African population has grown at a rate of approximately $2,5 \%$ per annum - a growth rate which annually adds another 1,2 million people to the country's population. World Bank estimates indicate that the average annual GDP growth rate declined from 3,2\% for the period 1970 1980 to $0,9 \%$ during $1980-1993$. Allowing for the above population growth rate, a negative average annual growth rate of $-0,2 \%$ in GNP per capita was estimated for the period 1980-1993 (Draft White Paper for a Population Policy, 1996:13). These figures point at a decline (instead of an improvement) in the standard of living of most South Africans in the recent past. Such a decline is likely to have been more acute among the economically disadvantaged groups, who constitute the majority of the population. As is the case elsewhere in the world, it is especially the poor, rural communities that are also inclined to show a high birth rate. In the deep rural areas of the Northem Province and KwaZulu-Natal a total fertility rate of six and higher is common (the average number of children per woman). This figure is almost twice as high as the world average.

The results of the high population growth rate can be found, for example, in soil erosion, the encroachment of the desert, deforestation and general socioeconomic degradation. As illustrated above, at the beginning of the 1990s South Africa, like most developing countries, was poorer in terms of per capita income than during the early 1980s. The situation was adversely affected by the political experimentation of the past, through which access to and distribution of resources were manipulated socially and politically along racial lines. Population pressure and the over-intensive management of agricultural land resulted in South Africa losing almost $25 \%$ of all available top-soil since the beginning of the century. Currently a further 300-400 million tons are anmually being lost (Salus, 1992:9). 
In a country where only an estimated $13,5 \%$ of the soil surface is suitable for crop cultivation, sustained food production to provide for the needs of the growing domestic requirements is indeed in jeopardy.

A few other environmental probiems facing South Africa include the following:

- The rapid eastward expansion of the Karoo, which can be attributed to the fact that this region is approximately $30 \%$ over-populated by cattle.

- The approximately 125 million tons of gas emission annually released by industries in the eastem regions of Mpumalanga, which causes some of the highest air pollution levels in the world.

- The more than 7 million cubic metres of firewood annually chopped down as the main source of fuel for 12 million rural and urban inhabitants.

If South Africa's problems with regard to the most valuable of all natural resources - water - are included, it is not to be wondered at that some observers summarize the situation in the country as "... nothing short of committing ecological suicide" (Sunter, 1992:153). To escape from this situation and to follow a path of sustainable development, nothing less than a change of value systems and life-styles will initially be required - a change that must above all be associated with the fostering of an environmental ethic among all South Africans.

\subsection{Indecent value systems and life-styles - the source of the environmental crisis?}

The interrelated issues of population growth, depletion of resources and pollution caused an ecological crisis - a crisis that does not merely originate from problems in the natural environment, but which also originates from problems related to economic systems, political choices and social inequalities. The immediate results of the ecological crisis extend over national borders: it is estimated that in 1991 there had already been more ecological fugitives in the world than political fugitives - a situation that will probably gain momentum in future (Gordon $\&$ Suzuki, 1991:100). This ecological crisis holds a threat to the integrity of natural systems of which human beings form part of, and therefore for the existence of mankind itself. Furthermore, it is a ecological crisis that is anchored in the crisis of the human "spirit". In other words, it originates from a crisis in the value system of mankind, and takes shape in the quest for materialistic life-styles.

Technological progress and economic growth, which brought about much prosperity and improved circumstances for many people, became the primary objectives of almost all societies. The effect that this has had on the environment is, however, often argued away or simply ignored. The solutions to the environmental crisis are therefore not to be found only in new technology, as we will see 
at a later stage, but also especially in the way we see ourselves and the environment around us. This poses an enormous challenge to policy-makers in their attempts to reconcile the needs and expectations of a growing population with the limitations of the natural environment. More specifically, it requires a revolutionary re-orientation in the technological, economic and socio-political arenas to make provision for the welfare of mankind and the survival of the planet. The ultimate objective is a sustainable society in order to ensure the chances of survival of the life-supporting ability of the earth and its inhabitants. Before the social requirements for such a sustainable environment are elucidated, it is necessary to focus briefly on the question: "What is sustainability?"

\section{What is sustainability?}

The concept of sustainability refers to the ability of a system to endure. However, it is not indicative of the attainment of a final end stage or a stable, "perfectly balanced" society. Much more relevantly, it implies "... a condition of dynamic equilibrium where perturbations are acceptable, even welcomed, in order to test the capabilities of the system (including a human system) to persist over the long term" (Reed \& Slaymaker, 1993:725). Sustainability can therefore be defined as the continuous working of certain necessary and desired properties of both the natural environment and the socio-political system. Therefore, to extend this definition, a sustainable environment may be said to be one that can exist over generations without the resource base becoming depleted, or pollution reaching such proportions that the natural environment's ability to absorb it is exceeded.

The concept of "sustainable development" is, however, more difficult to define due to its multi-disciplinary nature. In view of the fact that the concept of sustainable development is approached from different directions, there is much variation in the descriptions as the different disciplines usually emphasize unique facets. One description that is probably the most widely accepted, is that of the Brundtland Commission, officially known as the World Commission on Environment and Development (WCED - a commission which originated during 1987). This commission describes sustainable development as "... development that meets the needs of the present without compromising the ability of future generations to meet their own needs" (quoted from O'Riordan, 1995:22). Implicit in this view is the acceptance of a reasonable access by all populations to basic resources, both currently and in future. This means that poor communities must be given the opportunity for a sustained existence through, among other things, the transfer of applicable technology and capacity-building in science and management. This principle is also reflected in the following components of sustainable development as it is described by the WCED and recognized by the 
Economic Commission of Africa (a commission which came into being during 1987):

- Future generations must be taken into consideration in any planning process.

- Poor communities of the world must receive special attention.

- Special care must be taken to preserve a fair part of the current resource base for this and future generations.

In the light of the above it is clear that the environmental issues that were dealt with in paragraph two, all stand in the way of sustainable development; in other words, they are elements of non-sustainability It is especially the poor, and specifically the poor communities in rural areas of developing countries, which are forced to follow non-sustainable paths for the sake of survival. In Africa, including South Africa, sustainable development can only be achieved if the process includes the poor and marginalized communities and if it focuses on the improvement of the quality of life in such communities.

However, various studies have indicated that Africa is confronted by a series of interrelated economic and environmental challenges - a reality which indicates that development up to now has not been sustainable. The main factors that cause non-sustainable development in Africa can be classified, according to Kakonge and Imvbore (1994:2-5) under the following headings: drought and desertification, soil erosion, population pressure, poverty and political instability. The close relationship between the natural and the socio-political environments pointed out earlier, can be discerned in these factors.

The reality of this interrelationship also has the inherent implication that the necessity for sustainable development can no longer be regarded only in economic and techno-ecological terms. An interpretation of the problem that is mainly based on economic and/or ecological explanations and solutions, is biased and ignores the equally important role of social components in sustainability. In fact, Cernea (1994:7) points out that " failure to recognize the determinant role of the 'social actors' has doomed many programs trying to induce development". A plea for "putting people first" in the determination of policies and development programmes and even for direct involvement in development, is therefore no radical idea; it is rather a realistic one. It merely means that the central position of social actors and their institutions must be acknowledged and taken into account in sustainable development. In other words, sustainability must be "socially constructed"; that is, social and economic programmes must be implemented purposefully. For this reason the pursuit of a sustainable society must be approached as a triple task - socio-political, economic and ecological. The remainder of this discussion, however, will only focus on the social 
André Pelser \& Christo Heunis

component, although economic and political aspects may obviously also come into play.

\section{A paradigm shift in environmental views?}

Apart from the well-considered choice of technology and energy consumption, as well as legal limitations on resource utilization and pollution, sustainability also implies radically changed life-styles and values, whether this takes place voluntarily, out of necessity or both. A change in life-style (for example lower levels of consumption in order to counter the depletion of resources), however, would be so radical, that Nebel and Wright (1996:13) suggest a fundamental paradigm shift in man's view of the world. Paradigm shifts are important changes in the way in which people see the world and their place and role in it. Although paradigm shifts are associated with controversy and conflict during their initial presentation, a new era is subsequently introduced as knowledge and understanding increase. A few examples of such scientific views that brought about watersheds in people's way of thinking are the findings of Copernicus ("the earth revolves around the sun"), Newton ("all objects gravitate towards one another") and Darwin ("mankind is part of the animal kingdom").

The question arises whether we are now in the process of an even more significant paradigm shift, namely a shift from an "old" view of the world to a view that is focused on the environment. According to the "old" view, plants, animals, minerals and other resources exist for the exclusive purpose of serving human beings. To treat these resources merely as consumable resources would therefore not only be acceptable, but would in fact be the correct and proper way of doing things. It is further implied and accepted that there are no limits to consumption, and that conservation would therefore be unnecessary. This view of the world, which dates back to the early Judaic-Christian times, has over many centuries formed the basis of the economy and life-styles of Western civilization.

The world view propagated and promoted by those who are concerned with the environment is in almost every respect the antithesis of the "old" view. According to environmentalists the world (and therefore the availability of resources) is not limitless. Unlimited consumption is therefore not sustainable, which means that the continued welfare of mankind depends on conservation and protection programmes. In short, according to Nebel and Wright (1996:13) the new view implies a paradigm shift “... from seeing humans as the centre of things, free to ride over nature in any manner possible, to seeing nature as the centre and humans needing to learn to accommodate to it". This in fact means that developed countries (and developed communities/groups in countries) can no longer pursue their own economic interests and conveniently "forget" about the less developed countries/communities/groups as if they were separate entities which had no effect on the welfare and future of the rest. In the words of Gordon 
and Suzuki (1991:180) " that basically means the rich must live more simply so that the poor may simply live".

The appeal from environmental circles for a change in the values and life-styles of people for the sake of "general human interest" can, however, very easily fall into a vacuum. This cannot only be attributed to the irrational nature of mankind, but to the exceptionally unequal distribution of power to make a significant impact on global, or even local environmental changes. Consequently, numerous communities are automatically caught up in patterns of daily activity that can be destructive to the environment, such as the cutting down of forests for the collection of firewood. Only if investment in programmes such as job creation and electrification (to use the example mentioned previously) increases dramatically, will individuals be placed in positions where they can make a significant contribution with regard to energy options, for example.

\section{Social accents in sustainable development}

Ideally, environmental remedy, sustainable development and the alleviation of poverty should therefore complement one another as concurrent processes. In conjunction with this, various studies suggest that, with regard to the relationship between poverty and environmental degradation, the marginalization of rural communities is promoted by three factors especially, namely (i) high population growth; (ii) soil consolidation and modernization/mechanization in agriculture; and (iii) general inequalities with regard to ownership of land (Barrow, 1995:47). In order to break the circle of poverty linked to high population growth and environmental degradation, large-scale social reform - especially adequate social aid - will be necessary. With regard to this, Hansen (1994:337 - emphasis added) states the following:

We must create conditions - through selective, creative and ethically sound social investments - women and couples to seek a lower number of surviving children. If anything, no development assistance appears to yield higher economic returns and include more sustained economic growth than basic invesiments in human capital, i.e. primary and secondary education, appropriate extension services for both genders, and primary health care.

Development strategies can make an extensive contribution to achieving this goal by not only investing in the economic and technical requirements for sustainability, but also in the creation of socio-organisational structures. Seen broadly and more specifically, this means that specific social accents that have an effect on sustainable development must form the basis of development programmes. While policy-makers are considering ways to promote sustainable development, it is therefore of the utmost importance that strategies should be developed that recognize and address these social aspects in order to arrest the 
André Pelser \& Christo Heumis

downward spiral of increasing poverty and the degradation of the natural environment. Although the following accents in no way form a comprehensive list or represent a particular priority sequence, the critical areas could nevertheless include the following:

\subsection{Revision of value systems}

Individual and cultural value systems will have to be revised incisively, especially with regard to economic choices. The management and utilization of resources have until now been almost exclusively driven by the economy, without taking the consequences for the environment in general into account. The narrow focus on economic growth will therefore have to make way for a more balanced perspective, characterized by a focus on sustainable development, environmental health and quality of life. Such a change in values could, on the one hand, be brought about by extensive "resocializing actions" which in turn should lead to the internalization of strong environmental ethics as a result. On the other hand, and concurrent with this, pressing and visual statutory intervention on the part of the government, aimed at crucial issues regarding population, pollution and the depletion of resources, will have to be the mainstay of any information programme

\subsection{Curbing of population growth rates}

Stability in population growth must enjoy priority in all countries. This is not only applicable to developing countries, but also to the industrialized countries where the populations use a disproportionately large part of the earth's resources and yields. There is no hope for a sustainable society if population growth rates do not drop to at least replacement level, and no hope for sustainable development in rural areas without stability in population growth among rural populations.

\subsection{Expansion of human rights}

Basic human rights, and in particular women's rights in developing countries, will have to be fully expanded on a universal scale. By ensuring that all women enjoy the full range of social, economic and political opportunities, environmental problems will be addressed in two ways. In the first instance, such action will sharply accelerate the pursuit of global population stability, as an increase in the socio-economic status of women is directly linked to a decrease in fertility rates. Secondly, all potential talent is required for the establishment of a sustainable society. Consequently, the loss of any individual potential that could make a contribution to this attempt cannot be afforded. Ultimately the expansion of basic human rights to all women will, among others, require an obligation from governments in developing countries to ensure that women enjoy access to 
Towards a sustainable society: a profile of social accents

educational institutions and proper health care - access they are still denied in many of these countries.

\subsection{Alleviation of poverty}

The alleviation of poverty, especially in rural areas, must be actively supported. Higher levels of income will enable the poor to consider long-term options, which in turn would also yield better dividends for resource utilization. In conjunction with this, authorities will have to ensure that macro-economic policy directions that have the objective of addressing poverty through stable and broad income growth do not discriminate against agriculture as the most basic labour-intensive sector. Job creation and income growth, even under the most favourable circumstances, can take several decades to alleviate poverty significantly without destroying the sensitive environmental regions (any further). There is therefore a need for directed policy guidelines regarding the immediate utilization of recources, as well as the production risks that poor, rural communities will be faced with and which may lead to the (further) deterioration of the environment

\subsection{Universal education, health services and family planning}

Improved access to education, health and family planning - which are fundamental to most of the strategies to alleviate poverty - takes a central place when environmental interests are considered. Access to quality education could potentially encourage the more judicious utilization of resources and at the same time, could increase the options for the generation of income, other than through the utilization of natural resources. Furthermore, access to public health services and information would enable poor communities to take measures that would lower environmental health risks. In addition, an increase in the funding of family-planning programmes would contribute towards counteracting, to some extent, the potential of high population growth to aggravate the deterioration of the environment.

\subsection{Availability of resources}

Improved access to services and infrastructure could reduce the environmental problems that face the poor (especially women). In this regard, the redistribution of and access to natural resources, in particular, should be scrutinized. In this way, for example, the redistribution of land would create more job opportunities and reduce the extent of migration to sensitive resource areas. In practice, however, redistribution often involves extensive social upheaval and uncertainty that are often met with resistance by those who have vested interests in it. A favourable environmental impact could possibly be brought about by concentrating on situations where uncertainty already exists with regard to property rights or where redistribution can rapidly take place. 


\subsection{Community involvement}

Because people are the beneficiaries as well as the victims of all development activities, their active participation in the development process is the key to success. If we do not realize the need for the promotion of the welfare of people by means of a strategy of "putting people first", environmental programmes are doomed to fail. The poor in particular are apparently hit the hardest by environmental degradation, while they are also the least equipped to protect themselves. At the same time, however, the poor also cause much of the damage to the environment because of their ignorance, lack of resources and a short-term disposition with regard to survival. The challenge lies in actively obtaining participation in development projects. More specifically, according to Serageldin (1994:5), such involvement entails progress on three levels:

- Firstly, those who will potentially be affected by development programmes must become more involved in the designing phase of the programmes.

- Secondly, local expertise must be utilized better in the designing and implementation of programmes.

- In the third place it is necessary to build capacity in order to determine the social impact of policy points and investments.

Ultimately, a strategy of "putting people first" contains an inherent promise of lasting sustainability of development programmes and better environmental management.

\subsection{The presence of a political will}

Especially in South Africa it is of crucial importance to realize that addressing environmental and, specifically, population issues with a view to sustainable development cannot take place in isolation from the wider political transformation in the country. After all, sustainable development must grow from a political will. The challenge lies in the establishment of an environmental and population policy which is free from any hidden political agendas and vested interests - a policy that can serve as a framework to improve the quality of life of many South Africans. Seen this way, there can only be talk of sustainable development and eventually of survival if the essential changes in value systems as a prerequisite firstly gain acceptance on government level and among policy-makers.

\section{Conclusion}

Apart from the fact that South Africa reflects various manifestations of an environmental crisis, the nature of the crisis is locally complicated by the sociohistorical context of the society. More specifically, the South African environ- 
ment is the victim of socio-political policy orientations of the past. A policy that was based on favouritism and disparagement eventually caused a melting-pot of environmental problems that show characteristics of both the problems of industrialized countries and those of developing countries. In the past, for example, actions taken by the authorities to address some of these problems (for example the Population Development Programme aimed at the high fertility rate) were greeted with scepticism in certain circles because of a lack of political legitimacy and acceptability in the broad social context. Such "development programmes" were then also often associated with authoritarian and unilateral actions, without involving those persons who were directly affected as participants in the development process.

In the essential search for sustainability it is important to avoid the mistakes of the past. Because the central authority, to a great extent, determines the climate for success, the broadest possible political legitimacy in conjunction with a collective political will is of cardinal importance. Furthermore, the search for sustainability must be founded on an approach that focuses on people, in other words one in which all development actions are aimed at the improvement of the quality of life of human beings within a quality environment. Only then will the path be prepared for a change in values among the broader community - a change that will be decisive in respect of the survival of the planet and its inhabitants.

\section{Bibliography}

BARROW, C.J 1995. Developing the environment: problems and management Essex : Longman Group.

CAPRARO, I. 1995. Die aarde se wateremmer loop leeg Die Volksblad: 4, Aug. 12.

CERNEA, M M. 1994 The sociologist's approach to sustainable development. (In Serageldin, I \& Steer A., eds. Making development sustainable: from concepts to action. Washington: World Bank. p. 7-9.)

DRAFT WHITE PAPER FOR A POPULATION POLICY 1996. Government Gazette, Oct 31 .

DYSON, T 1994. World population growth and food supplies. International Social Science Journal, 141:361-385

GORDON, A \& SUZUKI, D. 1991. It's a matter of survivial Massachusetts : Harvard

HANSEN, S 1994 Population: its challenge to economic and social scientists International Social Science Journal, 141:331-341.

KAKONGE, J O \& IMVBORE, A.M. 1994. Achieving sustainable development in Africa Lesotho Social Sciences Review, 1(1):1-11

LASS, M 1995. Population and development. Africa Insight, 25(1) 2-3

NEBEL, B.J. \& WRIGHT, R T. 1996 Environmental science: the way the world works. Upper Saddle River : Prentice Hall

O'RIORDAN, T. ed 1995. Environmental science for environmental management London: Longman

RAVEN, P H, BERG, L R \& JOHNSON, G B 1993. Environment New York: Harcourt Brace Jovanovich 
André Pelser \& Christo Heunis

REED, M.G. \& SLAYMAKER, O. 1993. Ethics and sustainability: a preliminary perspective. Environment and Planning A, 25:723-739.

SALUS 15 (13), July 1992. Department of National Health and Population Development Chief Directorate : Population Development.

SERAGELDIN, I. 1994. Making development sustainable (In Serageldin, I \& Steer, A eds. Making development sustainable: from concepts to action. Washington : World Bank. p. 1-5.)

SUNTER, C. 1992. The new century: quest for the high road Cape Town : Human \& Rousseau 